\title{
PROFESSIONALISM
}

ISSN: 1893-1049

Volume 10 , No 2 (2020), e3447

https://doi.org/10.7577/pp.3447

\section{Prestige hierarchies and relations of dominance among health professionals}

Anette Lykke Hindhede ${ }^{1}$ \& Kristian Larsen ${ }^{2}$

1. Aalborg University, Denmark

2. Copenhagen University Hospital, Denmark

Contact: Anette Lykke Hindhede, Aalborg University, Denmark, alh@learning.aau.dk

\section{Abstract}

Reflecting on Bourdieu's theory of symbolic power, the aim of our study was to determine the degree to which prestige ranking follows a logic of social recognition that transcends health professional group boundaries. Based on a previous cross-sectional survey, in which 605 health professionals ranked 19 diseases and 17 specialties, this paper draws on data from 25 in-depth interviews with nurses, doctors and nursing/medical students with the objective to understand to what degree each of the four groups dissociates themselves from the prestige ranking demonstrated in the survey. We found that all four groups have similar perceptions of prestige. However, while doctors and nurses defend the hierarchy of specialisations in medicine, medical students and nursing students to a greater degree challenge the status quo. This has no real impact, as their dissenting opinions are articulated from positions defined by their rank in the distribution of capital. Therefore, these positions cannot significantly threaten the stability of the healthcare field.

\section{Keywords}

Bourdieu, health professionals, heretical discourse, prestige, social closure, social space, symbolic power 


\section{Introduction}

Scholars have found that medical specialties are informally ordered in a prestige hierarchy (Album \& Westin, 2008; Album, Johannessen \& Rasmussen, 2017; Hinze, 1999; Norredam \& Album, 2007; Rosoff \& Leone, 1991; Shortell, 1974) with surgery and cardiology ranking at the top and dermatology and psychiatry at the bottom. In addition to a hierarchy of specialties, it has also been shown that doctors and final year medical students rank diseases according to prestige (Album \& Westin, 2008). In this work, factors related to the characteristics of a disease, such as organ location, aetiology, chronicity and treatment possibilities, were of importance for the ranking, along with other factors related to the characteristics of the patient, such as age, gender and risky behaviour. Their analysis showed that diseases associated with technologically sophisticated, immediate and invasive procedures in vital organs located in the upper parts of the body are given high prestige scores, especially where the typical patient is young or middle-aged. At the other end, low prestige scores are given to diseases associated with chronic conditions located in the lower parts of the body or having no specific bodily location, with less visible treatment procedures and where the typical patient is elderly.

Thus, while it has been demonstrated how doctors and final year medical students order medical specialties and diagnoses in a prestige hierarchy, less is known about whether these valuations are shared by close collaborators in the healthcare sector. Prestige is an important construct for the professions. The work of Weber on social closure has been extended by Larkin (1983), Freidson (1970), Parkin (1971) and Witz (1992), among others, to apprehend the mechanisms and strategies social groups employ in order to maximise rewards by restricting access to opportunities and singling out certain identifiable social and/or physical attributes as the basis for exclusion (for further discussion on the theory of social closure see Flemmen, Toft, Andersen, Hansen, \& Ljunggren, 2017). Following Weber, individuals are located hierarchically in society by the virtue of status (stände), which is determined by a collective estimation of honour. The division of labour "gives rise to characteristic differences in power, and power begets privilege, and power and privilege begets prestige" (Treiman, 1977, pp. 5-6).

Thus, the notion of prestige can be considered a status-ordering phenomenon. This logic of social recognition arises only "when certain attributes are interpreted through value judgements and organized into a hierarchical order" (Zhou, 2005, p. 97). In line with neoWeberian ideas of the formation of prestige hierarchies through social closure, Lamont (2012, pp. 204-5) argues, "subprocesses of (e)valuation include categorization dynamics, such as classification, commensuration, equivalence, signaling, and standardization (...) and legitimation dynamics, which includes the contestation and negotiation of value as well as its diffusion, stabilization, ritualization, consecration, and institutionalization." Thus, the logic of social recognition might "generate divergence and contention, rather than consensus, in social judgment among groups" (Zhou, 2005, p. 97). Following these 
arguments, the groups collaborating closely with doctors in daily hospital practice may or may not reproduce doctors' ranking of specialties and diagnoses. To be sure, the doctornurse relationship has often been described as a dominant-subservient relationship (Gjerberg \& Kjølsrød, 2001). To gauge the evidence for the existence (or absence) of consensus in health professionals' prestige order, we investigated how do doctors, nurses, medical students and student nurses within Danish public healthcare value specialties and diagnoses. We reproduced the research design created by Album and Westin (2008) and asked 605 respondents (nurses, doctors, nursing students, and early, mid and late-phase medical students) to rank diseases and specialties on a scale of 1 (lowest prestige) to 9 (highest prestige), based on how they believed most health personnel would rank them. We found prestige rankings similar to those of Album and Westin (see Attachment 1 for the results). While this may indicate a consensus in social judgment among the groups, it offers few clues as to how meaning production is constructed and how knowledge and beliefs are diffused within each group (Hindhede, 2019; Montgomery, 1991). In order to inquire if and how the valuation is contested and negotiated, in this paper, we ask, to what degree can or will nurses, doctors, and nursing/medical students dissociate themselves from the social recognition of medical diagnoses and specialties?

\section{Theoretical background}

As with previous Norwegian research on prestige hierarchies, our focus is not on practices but on discourses. This paper takes as its starting point that in order to investigate whether voices and language break with the legitimate language of the social world and common sense, a relational way of thinking is needed. To accomplish our analytic work, we draw on Pierre Bourdieu's studies of the cultural valuation of symbolic goods and social practices, in which he developed the concepts of "doxa", "orthodoxy" and "heterodoxy" (Bourdieu, 1977, pp. 159-71) (see Figure 1). These concepts enable us to analyse how the processes of production and reproduction of discourse happen.

Bourdieu makes a distinction between the universe of the undiscussed and the universe of opinion. To him, doxa is the universe of the undiscussed and undisputed; it represents the taken-for-granted assumptions in social space; it defines what is thinkable and sayable. Bourdieu (1977, p. 169) links doxic eruption into discourse in situations to "the existence of competing possibles and to the explicit critique of the sum total of the alternatives not chosen that the established order implies." Here, doxa is questioned by an opinion-ruled discourse, a heterodoxy seeking to expose the arbitrariness of the taken for granted. Orthodoxy, on the other hand, "aims, without entirely succeeding, at restoring the primal state of innocence of doxa" (Bourdieu, 1977, p. 169).

Social spaces are "multidimensional distributions of socially efficient properties (capitals) which stipulate a set of patterned positions from which one can intelligibly predict strategies" (Wacquant, 2020, p. 17). The question of the legitimacy to define the stakes and 
trump cards of the game "arises from the very possibility of this questioning, of a break with the doxa that takes the ordinary order for granted. Having said this, the symbolic strength of the participants in this struggle is never completely independent of their position in the game" (Bourdieu, 1985, p. 734). Dominant positions in social space can be characterised by an orthodox position striving to defend their own privileges by rejecting heterodox positions (dominated positions) that challenge the game, the rules of the game and the doxa. As pointed out by Bourdieu (1989, pp. 20-23) there are "symbolic struggles over the power to produce and to impose the legitimate vision of the world," to "create visions of division (...) through the words used to designate or to describe individuals, groups or institutions." Bourdieu's concept of symbolic power "addresses the consequential categorization, the ability to make the world - to preserve or change it - by fashioning and diffusing symbolic frames, collective instruments of cognitive construction of reality" (Wacquant, 2020, pp. 1819).

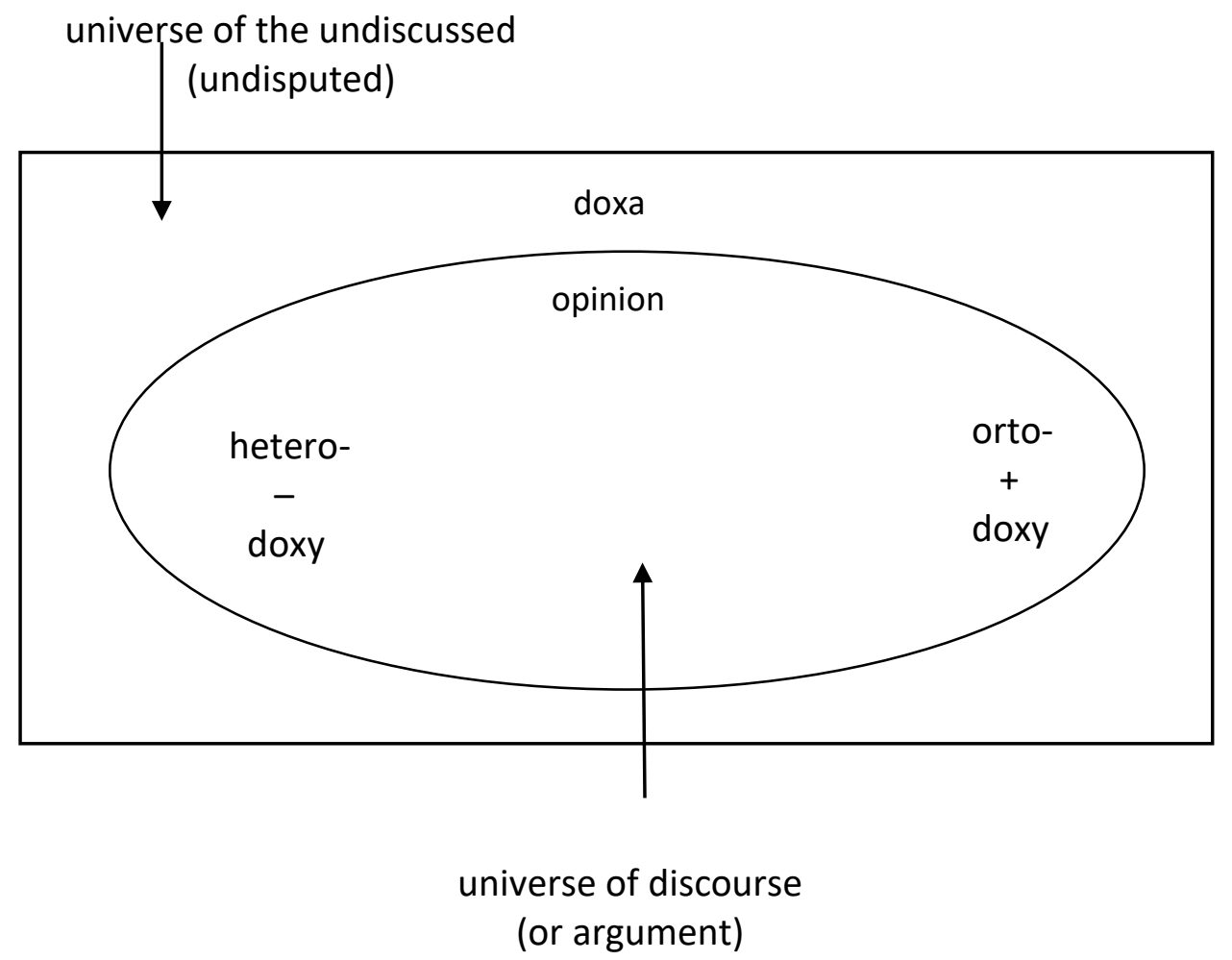

Figure 1: The relationship between heterodoxy, orthodoxy and doxa (Bourdieu, 1977, p. 168).

\section{Methods and analytical strategy}

In order to inquire into the universe of discourse among health professional regarding a social recognition of a prestige hierarchy of specialties and diagnoses, in this paper we draw on in-depth individual interviews with eight hospital-employed doctors (representing 
specialties within surgery and general and internal medicine), three hospital-employed nurses (within diabetes, intensive care and surgery), five nursing students and eight medical students (early, mid and late phases), acknowledging a slight over-representation of doctors and medical students. The interview participants were conveniently sampled among survey respondents to consider the various sources of norms and attitudes towards the ranking of medical specialties and diagnoses and why some were valued as being worthier than others. The interviews were informed by the results of the survey, which were presented to the interview respondents (see Appendix).

In the analysis of the interviews, we focused on how differences in prestige were articulated and made logical. All transcripts were coded in NVivo. In the coding process, the nodes that were used the most where "implication of hierarchy," which holds different stances on how the hierarchy influences society and the healthcare sector. "Specialty prestige" was also used a lot; this node holds stances on which specialties are considered prestigious as well as explanations for why that is, even though the explanations were mostly categorised in subnodes if the statements were unambiguous. Ambiguous statements were categorised in the head node "specialty prestige."

In our analysis, we first present our inductive analysis of the interviews and the four representations of reactions and comments in relation to the results of the survey. Then we conduct an epistemological break and relate the representations to the social space in which the group is positioned, and draw on figure 1 and the relationship between heterodoxy, orthodoxy and doxa in order to consider to what degree the doctrines constructed in the survey can or will be dismissed by the four positions of professionals in social space, the characteristics of this position, its point of view (about prestige hierarchies), its perception of the valuation of specialties and diagnoses, and how it values patients.

As this project did not involve clinical interventions, according to Danish law, no formal ethical clearance was required (please see Act on the Scientific Ethical Treatment of Health Sciences Research Projects 2017, \$14, Stk2.). We did ensure that the research was ethical: we obtained informed consent prior to the interviews, we ensured anonymity and we told participants that they could withdraw from the study at any time.

\section{Findings}

\section{Doctors in an orthodox and dominating position}

For the group of doctors, specialties where treatment is lifesaving and acute were considered very prestigious. Several of the doctors, both male and female, explained, "there is something about having other people's hearts and brains in your hands." Cancer and heart disease were mentioned as prestigious diagnoses partly due to the large amount of money spent on their treatment, as "they are an economic priority of the government." 
Several of the doctors explained that these diseases have large and resourceful patient groups that successfully brand them and raise funds with grand charity shows on TV, which also raises public awareness. The doctors also agreed that anaesthesia is considered a very prestigious specialty for several reasons. As one doctor put it, "these are the people you call in when everything else has gone wrong and the situation is going haywire." In addition, some of the doctors considered anaesthesia a very complex specialty. Anaesthesiologists, along with paediatricians, are often portrayed in the media as heroes who save the day. According to several of the doctors, this contributes to the prestige of these specialties. Psychiatry, on the other hand, is not valued as particularly prestigious, and the reasons given for this are the long-term treatment, the difficulty of measuring whether or not the patient actually recovers, the stigma attached to the patients, and the fact that it is a difficult group of patients in general. However, the prestige of this speciality is currently growing, as suggested by some of the doctor respondents here.

In general, the doctors distinguished between the various types of person behind the different types of speciality. One doctor (pathology) talked about how pathology is a "club of geeks," and several spoke about the field of surgery as being very male-dominated, especially a few decades ago. Abdominal and orthopaedic surgery are still male-dominated, and these surgeons were described as "swaggering people" with a cynical, non-empathetic approach to both colleagues and patients, and as having a very different culture from the gynaecological-obstetric and pathology doctors, who were described as "softer, more empathetic, and less competitive."

One doctor (respiratory medicine) talked about endocrinology not being particularly prestigious because of the non-specific lung patients who are included in this specialty "because nobody else wants them." This type of unspecified lung patient is considered "not interesting" and "bad for business" because there is no funding attached to this type of patient. According to one of the doctors (gastroenterology), the prestigious specialties attract outgoing, attention-seeking people who thus maintain their prestige. It came as a surprise to many of the doctors that lung cancer is at the top of the ranking (see Appendix), as they valued it as a "self-inflicted loser disease." Several of the doctors also mentioned "wastebasket diagnoses," which are diagnoses that cannot be treated because they are actually not possible to diagnose specifically (Jutel, 2011, p. 30).

In a social space perspective, it is obvious that the group of doctors share experiences with respondents in former studies of medical prestige hierarchies (Album and Westin, 2008; Album et al., 2017). Doctors-with certain limits-rule the game on the clinical level and they articulate values and prestige in social space from a "we" or "I" position. Overall, they represent an orthodox and dominating position as they have set the norms of prestige for 200 years (Foucault, 2002; Pinell, 2011). But doctors are also differentiated in 38 medical specialties (Sundhedsvidenskabeligt Fakultet SDU, 2010), and within these there are opposed experiences of prestige as we also saw in the interviews. Therefore, the 
battleground is two-fold for the doctors: they struggle with each regarding the relative prestige of specialties, but also with politicians, administrators and patient groups (Collyer, Willis \& Lewis, 2017). However, in general they see themselves as primarily defending the fellowship of doctors rather than providing an internal critique of colleagues and other specialties (Bayer \& Larsen, 2004). They do not perceive doxa as arbitrary. Instead, privilege is to some degree naturalised and made self-evident, shaped by their ancestors (doctors) and the wider context of social space. As Bourdieu explains, the self-evident "goes without saying and therefore goes unquestioned' (Bourdieu, 1977, p. 166).

\section{Medical students in an orthodox and dominated position}

The medical students agreed that specialties that perform life-saving treatments are considered the most prestigious. Surgeons are considered very prestigious because they "have a craft; they fix things and are seen as heroes in the public eye." Moreover, "they have a task, they perform it, and it is easy to see if they fail or succeed, so their work is very measurable, which is prestigious." Some of the medical students mentioned that surgery is becoming less invasive, with robots doing much of the work. This development is seen as interesting, but one of the medical students expressed disappointment that "the craft is disappearing and that the prestige of surgery may shift due to this development." Their reasoning for psychiatry rating low in prestige is that the work of this speciality is intangible, and "it is not that clear what psychiatrists actually do." A handful of the medical students talked about these doctors as "shrinks who prescribe medicine to patients who will never get well anyway." However, another handful posited that psychiatry will become more popular due to an increasing fascination with the mind and brain. According to these medical students, the vital organs, for example, brain, heart, lungs and kidneys, are very prestigious to work with, as opposed to the psyche and the skin. There was disagreement within this group about internal medicine. Some thought internists merely prescribe medicine, whereas others considered them to be very prestigious because they are the ones who figure out the most important determinant for a patient's treatment, the diagnosis, which is seen as a very complex and difficult task that demands a broad skillset and a sharp mind.

Geriatrics is regarded as low in prestige and "not that sexy because the diseases this patient group has [are] often just the result of a long life." Nevertheless, one student suggested that geriatrics could become more prestigious in the future because the elderly segment of the population is increasing. Many students also argue that paediatrics is prestigious due to the majority of medical students being female. The patient group, children, is also prestigious because "they can be difficult to work with" and "saving a child is more noble than saving an elderly person."

A majority of the medical students talked about how their personal interest is the only element that guides them in their choice of speciality, although a couple of them reflected 
upon how society's view of prestige might influence them. Approximately half of the students talked negatively about the hierarchy within the world of medicine and problematised how the differences in prestige influence the allocation of resources in a harmful way. Some specialties, such as psychiatry, suffer from this, and others benefit from it. One of the mid-phase medical students explained the allocation of funding as follows:

Oncology and "heart" receive far more money than psychiatry and geriatrics. Society is only concerned about the patients and the areas where we can make a significant difference. Psychiatric and geriatric patients suffer from dementia or other types of chronic mental illnesses we cannot cure. The impact of these patients being placed in a psychiatric ward or not is not that grand. Nevertheless, I'm thinking that the means are distributed unevenly and of course that's not good.

Seen from a symbolic power perspective, the medical students are not yet powerful possessors of the right kind of capital, but they are on their way-according to the progress of their study. They are not yet fully socialised in social space. Although their habitus is shaped by different ethnic and socio-economic backgrounds (Bayer \& Larsen, 2004), they have no interest in being heretics and display a radical and ground-breaking critique of the rules of the game. They do not challenge the doxa, as medical school shapes them not only to accept but also to support the doxa (Becker, 1961; Luke, 2007). They strive to "learn" and thereby achieve the necessary capital, enabling them to convert the position from "in process" to "product" (from a medical student to a doctor). This position makes space for challenging certain aspects, such as the unequal allocation of resources to various patient groups, while concurrently accepting the doxa. Their comments on psychiatry are illustrative: statements such as "it is not clear what psychiatrists actually do" were followed by forecasting that this specialty may grow in prestige due to their own fascination with the mind and the brain.

\section{Nurses in an equivocal and dominated position}

The nurses showed patterns partly similar to those of the doctors. One nurse (diabetes medicine) noted that it is prestigious to save lives and to have a high treatment rate. She wondered why anaesthesiology was so prestigious in the study (see Appendix), but thought it might have something to do with saving lives. She also mentioned that neurosurgery is prestigious because it is difficult and complicated. According to this respondent, general medicine is often referred to as "the bin," but she thinks it is prestigious "because in this specialty you are supposed to be able to do everything all at once." Specialties like heart surgery and lung surgery were considered particularly prestigious because politicians are interested in them and allocate many resources to their treatment. One of the nurses (intensive care) emphasised that it is not the most prestigious to only be good at the 
technical side or to only be good at human contact: "What is prestigious is if you can handle both, especially for us nurses."

One nurse (surgery) stated that she was in doubt as to whether she ranked the specialties and diseases according to how prestigious she thought they were or whether she was influenced by the way in which they are generally talked about. She found it difficult to be objective when she herself is "part of the system." In the interviews with the three nurses, it was repeatedly mentioned that political interest makes a specialty more prestigious and therefore better as it gains more resources and increases in quality. This relationship is explained in the following quote: "The specialties that are low in prestige are occupied by the youngest and least qualified nurses, I have no doubt about that." The nurse (internal medicine) further noted, "it is often those without experience that end up in the same place, resulting in poor quality." Thus, the nurses agreed that the specialties that have many research benefits also provide better quality. Psychiatry was mentioned as a very difficult specialty that should be more prestigious than it was rated in the survey. This was not because of a difficult-to-treat patient group or due to being able to save lives, but rather because research in psychiatry is difficult to conduct as "the group of patients react in inappropriate ways." In the future, however, psychiatry could become more prestigious "as politicians are increasingly focusing on this specialty." In addition, infectious medicine could become very prestigious in the future because of the increasing amount of research in the field. One of the nurses (intensive care) explained that she believes many end up in their specialties because of where they had their internship. Another nurse (surgery) said that she found her specialty through a random job post. One thing all three nurses emphasised in their work is seeing patients as "human beings" and aiming to "prioritize human contact." For example, one of the nurses (intensive care) said she could not be a surgical nurse as the patient progress is too short. Another of the nurses (internal medicine), who was "particularly interested in the medical specialties" was well aware that "it is not as prestigious as the other more acute specialties." This was also evident by the fact that her ward receives few resources, which is reflected in the quality of the care. For example, the physical framework of the ward is being prioritised, which leaves no room for elderly patients, with their walking frames in the toilets. She believes that the reason for doing nothing about this problem is that these patients do not criticise the sector, which means that it does not receive political attention. In addition, she works with patients whose diseases are referred to as lifestyle diseases, which causes the patient group to become stigmatised and less prestigious. The media also influences what is considered prestigious to some extent, for example, cervical cancer due to the debate about vaccinations. Another of the nurses (intensive care) explained that she feels health professionals want to work where "things happen," for example, in the emergency departments. Less often do they want work on long-term treatments, such as with chronic patients. 
In a symbolic power perspective where power is "the power to constitute the giving by stating it, to show forth and gain credence, to confirm or transform the world view and, through it, action on the world, and hence the world itself" (Bourdieu, 1979, p. 82), we see how the nurses share the inside knowledge about "the given" gained by being part of the game in social space for several years. Their position is that of both an outsider and an insider: they provide first-hand observations of the game over the years, but can also, like anthropologists, describe and map the practices and relations of dominance. As part of this they can to some degree also understand and explain why things are as they are. According to Bourdieu, heretics may be beholden to the most insignificant of positions. The nurses talk from a dominated position in social space that somehow follows the logic of the prestige hierarchy found in our survey; for example, the least prestigious specialties also "attract the youngest and least qualified nurses." However, the nurses emphasised and stressed that in their work they see patients as "human beings" and they prioritise "human contact." The nurses' position is equivocal as it is located "between" being part of and apart from the game. This is articulated as an ability to see and understand what is going on, while at the same time accommodating the fact that this is an observer position without the ability to challenge the field structure or the rules of the game. Thus, they are not real heretics, able to "fulfill the dual role of dupes and decipherers of doxa" (Berlinerblau, 2001, p. 349).

\section{Nursing students in a heterodox and dominated position}

The inductive coding of the interviews with the five young nursing students also showed partly similar valuation patterns to those of the doctors, medical students and nurses. The medical specialties referred to as prestigious have in common that they are very complex. However, the nursing students did not agree on which specialties are most complex, but agreed that complexity should be equal to prestige. Several nursing students said that one should rank prestige for how complex a specialty is, but that this is not always the case. They agreed that anaesthesiology is prestigious. However, one nursing student disagreed with this assessment because, in her opinion, anaesthesia is just like following a recipe, and therefore not very complex. The definition of complexity varied slightly among the students. Neurosurgery and brain disorders were mentioned as prestigious, because "the brain is very complex" and "there are many things we still do not know about the brain." General surgery was also considered prestigious by most nursing students. However, one of the respondents (early phase) stated that general surgery is "just like a craft where you just follow a recipe." She considered psychiatry more prestigious than its score suggests because "it is much more complex." Her fellow students spoke of psychiatry with great respect for those who work in the field, but stated that it is not prestigious because "it's not measurable," "the results are slow" and "you do not save lives." In psychiatry, depression is often referred to as a disease that is stigmatised. One of the nursing students (early phase) related an experience from her internship in psychiatry in which the doctor was "completely crazy," and the reason he was not replaced was that "there is no one who wants to work in psychiatry." As with the doctors, nursing students also mentioned the media's influence on prestige in terms of 
specialties, but particularly in relation to diseases. Another of the nursing students (late phase) explained, "the specialties and diseases that receive many resources often get good results, which can lead to prestige. This is problematic in that we put the same requirements on different specialties, as a palliative department's goal is not to save many lives, but to give patients a good end to life." Two of the nursing students argued that older people are not particularly prestigious patients, as "they require a lot of help with the basic things."

Several nursing students also mentioned that what they consider prestigious is very subjective and has to do with the specialties they are interested in. One of the nursing students is interested in anaesthesia because her mother is also a nurse in the field. They also spoke of how their internships and their friends' internship stories affect what they consider exciting. One of the nursing students (late phase) thought that prestige is linked to experience, continuing education, payroll and high treatment rates. Some of them considered progress and measurable results important, while others were more interested in the process. Some nursing students thought that prestige equals better quality, as these specialties receive more resources. Others believed that nurses will always do their best and provide good quality care, regardless of whether the subject is prestigious. One of the nursing students mentioned that she hopes that in the future humanistic and phenomenological values will receive the same recognition as the natural sciences currently do. In her opinion, doctors weigh scientific values highly, while nurses contribute more to the other values.

In a symbolic power perspective, the nursing students have the least capital-regarding both the amount and the composition - to be employed in social space (Larsen, 2000). They are new and low positioned and therefore also have the least to lose when talking about prestige in the healthcare sector. This position offers them the opportunity to say that "complexity should count" or that anaesthesiologists only "follow a recipe" or-pushing the limits of doxa even further (Bourdieu, 1977, p. 169)-arguing that "patients are human beings" or that doctors and nurses relate to natural science versus social science, respectively. These types of critical discourses bring the "undiscussed into discussion" (Bourdieu, 1977, p. 168). However, "it is only when the dominated have the material and symbolic means of rejecting the definition of the real that is imposed on them (...) that the arbitrary principles of the prevailing classification can appear as such" (Bourdieu, 1977, p. 169). Thus, this kind of positioning has no real impact in social space that is regulated by more powerful positions both physically present (doctors, administrators) and absent (political positions, pharmaceutical industry) (Larsen, Harsløf, Højbjerg, \& Hindhede, 2018). The nursing students do not yet really know the game, or rather the rules of the game. Doxa is embodied, lived and assumed whereas discourse is cognitively determined. As they lack experience with "the everyday order" and "with the language of order," these are situations that "call for an extraordinary discourse" (Bourdieu, 1977, p. 170) by heterodoxy. 


\section{Discussion}

Similarly to the Norwegian studies introduced by Album and colleagues (Album \& Westin, 2008; Norredam \& Album, 2007), we focused on health care professionals' representations of practice. In our study, all respondents were able to more or less adequately explain how the prestige hierarchy is configured as well as how societal, political and field-internal struggles are involved in the valuation of specialties and diagnoses. Overall, and in comparison with the Norwegian studies, integrating a large number of lower-positioned agents-nurses and nursing/medical students-did not significantly change the structure or the explanations of the medical prestige hierarchy.

In another Norwegian study, Haldar, Engebretsen and Album (2016) investigated discourse among doctors and found that doctors are able to present and discuss views on disease prestige in a way that would be considered illegitimate if they were declared directly. Comparatively, this study took a relational approach and explored the discourse among four groups of health professionals.

Our study indicates that there exist rules for how the struggle for gaining positions and capital is to be carried out, namely, that the least qualified nurses are in the least prestigious specialties, and vice versa. Harrits and Larsen (2016) argue that as the medical profession has strong historical ties to the Danish welfare state, the scientific knowledge base of this group makes it easier to make uncontested claims concerning cultural authority (such as arguments defending the reputation of the medical profession in the public domain). Law and Aranda (2010) found that occupational prestige for nurses may result in increased autonomy in decision-making related to patient care. However, a consensus on status criteria and status placement forms the basis of the overall occupational hierarchy within the healthcare sector. Our data suggest that stability is built (in relations) within medical institutions, medical professions and disease specializations. Nurses are still in a low position compared to doctors, despite increasing efforts towards the academization of nursing (Petitdit-Dariel, Wharrad \& Windle, 2014). Also, student nurses struggle to resist representations of their discipline as lacking legitimacy in the healthcare sector (Sollami, Caricati, \& Mancini, 2018).

We have characterised four positions of doctors, nurses, and medical and nurse students. These rough and general categories are organised around concepts of heterodoxy, orthodoxy, and doxa. However, analyses of positions in social space (in our case, doctors, nurses, and nursing/medical students) ideally need to be supplemented by reflection about diversity in habitual dispositions, background (occupation/student), gender (male/female), age (old/young), speciality, and work contexts as this contributes to what is considered the legitimate language of the social world.

In our analysis, we suggest that the nurses' position is ambivalent. Similar findings have been identified by Lalleman and colleagues (2016), who show how nurses' caring 
dispositions at times hinder their leadership abilities and thereby their achievement of a more dominant role in the healthcare field. According to McDonald, Waring, Harrison, Walshe, and Boaden (2005), modern nursing can be characterised by a closer identification with medical interests, values and practices. It is by defending their decisions and actions on a scientific rather than an intuitive or conventional basis that nurses bolster their claim to professionalism.

In our analysis, we have focused on utterances that could be considered as "heretical discourse," which is new language that breaks with the legitimate language of the social world and common sense. According to Grenfell (2011, pp. 62-63), "the efficacy of such 'heretical' language does not reside in the words themselves." Rather, following Bourdieu (1991, p. 129), it resides "in the dialectic between the authorizing and authorized language and the dispositions of the group which authorises it and authorises itself to use it." Thus, heretical language becomes authorised only through the "labour of enunciation," which must be considered meaningful and is, therefore, socially sanctioned by the group. In our case, all dominated groups were to various degrees able to "name the unnamable" (Bourdieu, 1991, p. 129). In so doing, they objectified "the pre-verbal and pre-reflexive in ways which render them common and communicable" (Bourdieu, 1991, p. 129).

Nonetheless, these groups were not able to destroy the self-evident truths of the doxa in social space. Rather, we were only able to identify a few symbolic struggles over the legitimacy of claims for placing specialties and diagnoses in a particular ranking, even within the large group of students. An explanation for this might be that both the medical and nursing students, during their educational programmes, internalise recognition of and deference to the commonly recognised attributes of what is prestigious and what is not. A follow-up study showed that apoplexy had increased its position in the prestige hierarchy over 24 years (Album et al., 2017), but overall, studies show a surprising constancy in the rankings, and we might ask why this is the case? According to Hindhede and Larsen (2019), the number of subfields in medicine (subfields of institutions, subfields of professions, subfields of diseases, subfields of technology, etc.) create a complex network that connects and stabilises the field, and each of these operates with relative autonomy within the broader social space. Here, all agents are equipped with a habitus that enables them to learn and recognise the rules of the game, the stakes and so on. They have general dispositions that are acquired through socialization and education and through practical experience. In order to achieve legitimacy, they must have recourse to many and varied strategies. However, they are differently positioned in the field, which offers different and opposed "conditions of possibility" (Bourdieu, 1990, p. 139) for strategies and for playing the game, including having opinions about the prestige hierarchy. In other words, the four groups all have the right to speak and are recognised in social space as possessors of capital, but the capital is unequally distributed among them. For the ones that represent heterodox discourses, their position offers the "condition of possibility" of being in opposition to the prestige hierarchy. Nonetheless, they obey the basic rules of the game; that some 
discourses are possible, other are impossible and some are unthinkable. They do not bring the undiscussed into discussion. They may be critical towards elements of the prestige hierarchy, thus representing heterodoxy to the established order, but the manifestation of censorship imposed by the orthodox discourse means that they reproduce many other discourses, such as blaming patients for self-inflicted conditions and agreeing that soma is more prestigious than psyche.

So, what is the value of Bourdieu's ideas about symbolic power struggles compared to, for example, neo-Weberian research on strategies of social closure and professional cultures (mentioned in the introduction)? Through the neo-Weberian lens, the professions are seen as highly motivated by benefits such as status, power and income, and are in competition with one another to secure these benefits. Bourdieu's concepts of social space and symbolic power, and the relationship between heterodoxy, orthodoxy and doxa help us see how stratification by status entails differences in social honour, and that such stratification tends to be associated with how professional knowledge is produced, legitimised and monopolised.

This study has other limitations that warrant consideration. First, we had (deliberately) very few respondents among nurses and doctors compared to the group of medical students and nursing students. However, even with very few respondents in these two groups, we were able to reproduce the findings from Norway (Album \& Westin, 2008). Another limitation is that only hospital-employed nurses and doctors were included in the sample. One might speculate that health professionals in other parts of the healthcare sector might represent more heterodox discourses on prestige hierarchies and the related groups of patients. In addition, while this is obviously beyond the scope of this paper as we do not have sufficient data, an elaboration on the various dispositions of the habitus of the four groups relating to their specific employment would be interesting.

\section{Conclusion}

In this study, we used Bourdieu's theory of social power to bring attention to the processes that may be misrecognised in research on medical prestige. We found that the four groups of doctors, nurses, and medical/nursing students had similar valuations of medical diagnoses and specialties. However, there were also intergroup variations of prestige judgements. While doctors defended the hierarchy of specialties in medicine, nurses, medical students and nursing students to a larger degree produced heretical discourses by challenging the status quo. As dominated positions, these groups have an interest in pushing back the limits of doxa and exposing the arbitrariness of what is taken-for-granted, such as not treating patients as human in the healthcare sector.

In terms of doxa, many respondents across the four groups indicated the norm that it is acceptable to have less respect for diseases that patients could have avoided if they had lived by rules pertaining to proper lifestyle behaviour. We do not have any data to say 
anything about how disease prestige relates to processes of prioritisation in the Northern European healthcare system. However, the doctor's oath to treat all patients alike is seriously threatened if the issue of guilt affects the priority of treatment. Moreover, some factors that affect the prestige of a medical specialty cannot be easily changed, such as the disease and body part being treated. Consequently, prestige hierarchies may act as an instrument of social stratification in that particular patient groups are being marginalised and put at risk because the specified diseases they are prone to might not be prioritised due to a socially sanctioned prestige hierarchy. In times when diseases and diagnoses are closely connected to economic resources and incentives, this is important for policy-making in the healthcare sector.

\section{Article history}

Received: 19 Jun 2019

Accepted: 24 Feb 2020

Published: XX Jun 2020

\section{References}

Act on the Scientific Ethical Treatment of Health Sciences Research Projects 2017, §14, Stk2. Retrieved from https://www.retsinformation.dk/Forms/R0710.aspx?id=192671

Album, D., Johannessen, L. E. F., \& Rasmussen, E. B. (2017). Stability and change in disease prestige: A comparative analysis of three surveys spanning a quarter of a century. Social Science \& Medicine, 180, 45-51.

https://doi.org/10.1016/j.socscimed.2017.03.020

Album, D., \& Westin, S. (2008). Do diseases have a prestige hierarchy? A survey among physicians and medical students. Social Science \& Medicine, 66(1), 182-88. https://doi.org/10.1016/i.socscimed.2007.07.003

Bayer, M., \& Larsen, K. (2004). Speciallægeuddannelse i Danmark: En empirisk unders øgelse af tendenser inden for speciallægeuddannelsen før implementeringen af den nye speciallægeuddannelse. Sundhedsstyrelsen og Danmarks Pædagogiske Universitet. (Education of medical specialists in Denmark: An empirical study of tendencies before the educational reform) Retrieved from https://www.sst.dk/ /media/F74C405348634059A6FAFA359ED54A87.ashx

Becker, H. S., Hughes, E., \& Strauss, A. (1961). Boys in white: Student culture in medical school. Chicago: Chicago University Press.

Berlinerblau, J. (2001). Toward a sociology of heresy, orthodoxy, and doxa. History of Religions, 40(4), 327-351. https://doi.org/10.1086/463647

Bourdieu, P. (1977). Outline of a theory of practice. Cambridge: Cambridge University Press. https://doi.org/10.1017/CB09780511812507

Bourdieu, P. (1979). Symbolic power. Critique of Anthropology, 4(13-14), 77-85. https://doi.org/10.1177/0308275X7900401307 
Bourdieu, P. (1985). The social space and the genesis of groups. Theory and Society, 14(6), 723-744. https://doi.org/10.1007/BF00174048

Bourdieu, P. (1989). Social space and symbolic power. Sociological Theory, 7(1), 14-25. https://doi.org/10.2307/202060

Bourdieu, Pierre. (1990). The Logic of Practice. Stanford, CA: Stanford University Press.

Bourdieu, P. (1991). Language and symbolic power. Cambridge: Polity Press.

Collyer, F. M., Willis, K. F., \& Lewis, S. (2017). Gatekeepers in the healthcare sector: Knowledge and Bourdieu's concept of field. Social Science \& Medicine, 186, 96-103. https://doi.org/10.1016/i.socscimed.2017.06.004

Flemmen, M. P., Toft, M., Andersen, P. L., Hansen, M. N., \& Ljunggren, J. (2017). Forms of capital and modes of closure in upper class reproduction. Sociology, 51(6), 12771298. https://doi.org/10.1177/0038038517706325

Foucault, M. (2002). The birth of the clinic. London: Routledge. https://doi.org/10.4324/9780203406373

Freidson, E. (1970). The profession of medicine. Chicago: University of Chicago Press.

Gjerberg, E., \& Kjølsrød, L. (2001). The doctor-nurse relationship: How easy is it to be a female doctor co-operating with a female nurse? Social Science \& Medicine, 52(2), 189-202. https://doi.org/10.1016/S0277-9536(00)00219-7

Grenfell, M. (2011). Bourdieu, language and linguistics. London: Continuum International Publishing Group.

Haldar, M., Engebretsen, E., \& Album, D. (2016). Legitimating the illegitimate: How doctors manage their knowledge of the prestige of diseases. Health, 20(6), 559-577. https://doi.org/10.1177/1363459315596798

Harrits, G. S., \& Larsen, L. T. (2016). Professional claims to authority: A comparative study of Danish doctors and teachers (1950-2010). Journal of Professions and Organization, 3(2), 154-169. https://doi.org/10.1093/jpo/jov011

Hindhede, A. L. (2019). Medical students' educational strategies in an environment of prestige hierarchies of specialties and diseases. British Journal of Sociology of Education, 41(3), 315-330. https://doi.org/10.1080/01425692.2019.1703645

Hindhede, A. L., \& Larsen, K. (2019). Prestige hierarchies of diseases and specialities in a field perspective. Social Theory \& Health, 17(2), 213-230.

https://doi.org/10.1057/s41285-018-0074-5

Hinze, S. W. (1999). Gender and the body of medicine or at least some body parts:

(Re)constructing the prestige hierarchy of medical specialties. Sociological Quarterly, 40(2), 217-239. https://doi.org/10.1111/j.1533-8525.1999.tb00546.x

Jutel, A. (2011). Putting a name to it: Diagnosis in contemporary society. Baltimore: Johns Hopkins University Press. 
Lalleman, P. C. B., Smid, G. A. C., Lagerwey, M. D., Shortridge-Baggett, L. M., \& Schuurmans, M. J. (2016). Curbing the urge to care: A Bourdieusian analysis of the effect of the caring disposition on nurse middle managers' clinical leadership in patient safety practices. International Journal of Nursing Studies, 63, 179-188.

https://doi.org/10.1016/j.ijnurstu.2016.09.006

Lamont, M. (2012). Toward a comparative sociology of valuation and evaluation. Annual Review of Sociology, 38(1), 201-221. https://doi.org/10.1146/annurev-soc-070308120022

Larkin, G. (1983). Occupational monopoly and modern medicine. London: Tavistock Larsen, K. (2000). Praktikuddannelse, kendte og miskendte sider: Observationsstudie af praktikuddannelse indenfor sygeplejerskeuddannelsen (1 udg.) (Education in practice, known and misrecognized sites: An observational study of learning in practice in nursing education) (Ph.D. dissertation). University of Copenhagen. København: UCSF. .

Larsen, K., Harsløf, I., Højbjerg, K., \& Hindhede, A.L. (2018). Health capital: An empirical study of Danish healthcare professionals' bodily investments. 548-549. Paper XIX ISA World Congress of Sociology, Toronto, Canada.

Law, K., \& Aranda, K. (2010). The shifting foundations of nursing. Nurse Education Today, 30(6), 544-547. https://doi.org/10.1016/j.nedt.2009.11.006

Luke, H. (2007). Medical Education and Sociology of medical habitus: "It's not about the stethoscope!". Berlin: Springer Science \& Business Media.

McDonald, R., Waring, J., Harrison, S., Walshe, K., \& Boaden, R. (2005). Rules and guidelines in clinical practice: A qualitative study in operating theatres of doctors' and nurses' views. BMJ Quality \& Safety, 14(4), 290-294.

https://doi.org/10.1136/qshc.2005.013912

Montgomery, S. L. (1991). Codes and combat in biomedical discourse. Science as Culture, 2(3), 341-390. https://doi.org/10.1080/09505439109526314

Norredam, M., \& Album, D. (2007). Prestige and its significance for medical specialties and diseases. Scandinavian Journal of Public Health, 35(6), 655-661.

https://doi.org/10.1080/14034940701362137

Parkin, F. (1971). Class inequality and political order: Social stratification in capitalist and communist societies. New York: Praeger Publishers.

Petit-dit-Dariel, O., Wharrad, H., \& Windle, R. (2014). Using Bourdieu's theory of practice to understand ICT use amongst nurse educators. Nurse Education Today, 34(11), 13681374. https://doi.org/10.1016/j.nedt.2014.02.005

Pinell, P. (2011). The genesis of the medical field: France, 1795-1870. Revue Française de Sociologie, 52(5), 117-151. https://doi.org/10.3917/rfs.525.0117

Rosoff, S. M., \& Leone, M. C. (1991). The public prestige of medical specialties: Overviews and undercurrents. Social Science \& Medicine, 32(3), 321-326.

https://doi.org/10.1016/0277-9536(91)90110-X 
Shortell, S. M. (1974). Occupational prestige differences within the medical and allied health professions. Social Science \& Medicine, 8(1), 1-9. https://doi.org/10.1016/00377856(74)90003-1

Sollami, A., Caricati, L., \& Mancini, T. (2018). Does the readiness for interprofessional education reflect students' dominance orientation and professional commitment? Evidence from a sample of nursing students. Nurse Education Today, 68, 141-45. https://doi.org/10.1016/j.nedt.2018.06.009

Sundhedsvidenskabeligt Fakultet SDU (2010). De 38 specialer. Temanummer om de danske speciallægeuddannelser. Sund og Hed, 12. Odense: Universitetstrykkeriet.

Treiman, D. J. (1977). Occupational prestige in comparative perspective. New York: Academic Press.

Wacquant, L. (2020). Bourdieu's dyad: On the primacy of social space and symbolic Power. In Blasius, Le Baron, Le Roux \& Schmitz (eds.). Empirical Investigations of Social Space. Basel: Springer Nature Switzerland. https://doi.org/10.1007/978-3-030$15387-8 \quad 2$

Witz A. (1992). Professions and patriarchy. London: Routledge.

Zhou, X. (2005). The institutional logic of occupational prestige ranking: Reconceptualization and reanalyses 1. American Journal of Sociology, 111(1), 90-140.

https://doi.org/10.1086/428687 
Appendix: Results of the survey

Specialties, all occupations

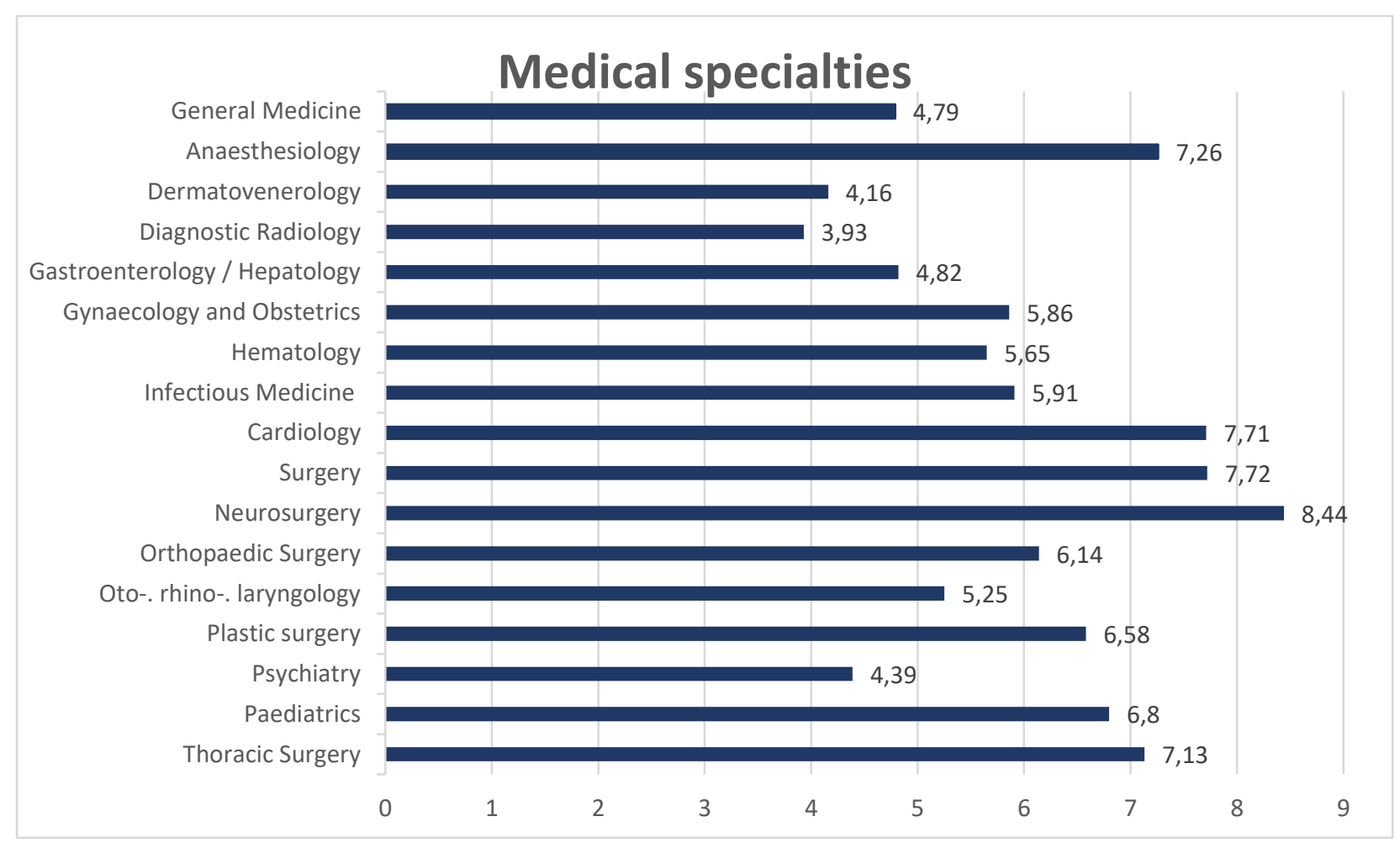


Diagnoses, all occupations

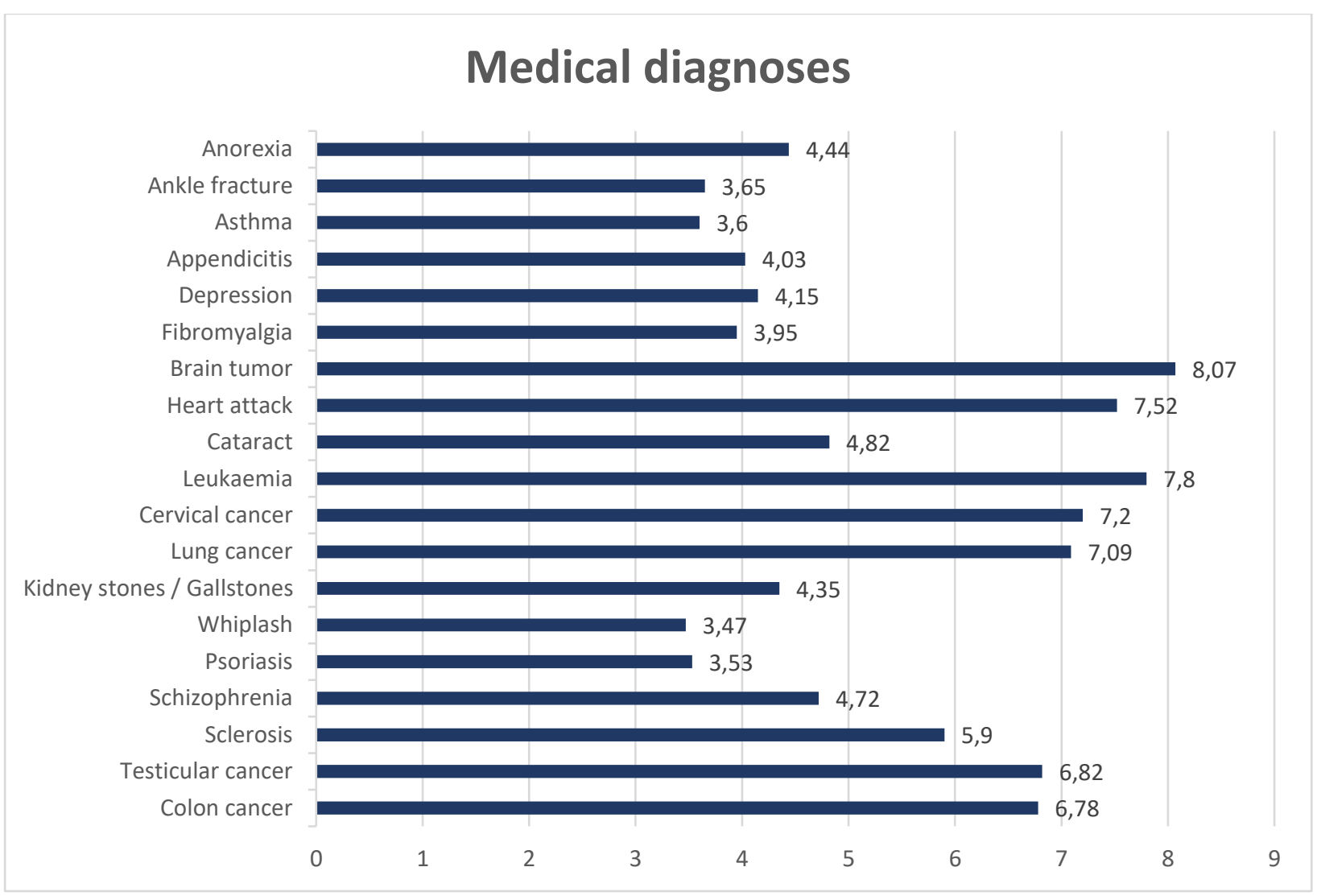

